\title{
Comorbidities, treatment patterns and cost-of-illness of acromegaly in Sweden: a register-linkage population-based study
}

\section{Eva Lesén', Daniel Granfeldt', Aude Houchard², Jérôme Dinet², Anthony Berthon², Daniel S Olsson ${ }^{3}$, Ingela Björholt' ${ }^{1}$ and Gudmundur Johannsson ${ }^{3}$}

${ }^{1}$ Nordic Health Economics, Gothenburg, Sweden, ${ }^{2}$ Ipsen, Boulogne-Billancourt, France, and ${ }^{3}$ Department of Internal Medicine and Clinical Nutrition, Institute of Medicine, Sahlgrenska Academy, University of Gothenburg and Department of Endocrinology, Sahlgrenska University Hospital, Gothenburg, Sweden
Correspondence should be addressed to E Lesén

Email

eva.lesen@

nordichealtheconomics.se

\begin{abstract}
Objective: Acromegaly is a complex endocrine disease with multiple comorbidities. Treatment to obtain biochemical remission includes surgery, medical therapy and radiation. We aimed to describe comorbidities, treatment patterns and cost-of-illness in patients with acromegaly in Sweden.

Design: A nationwide population-based study.

Methods: Patients with acromegaly were identified and followed in national registers in Sweden. Longitudinal treatment patterns were assessed in patients diagnosed between July 2005 and December 2013. The cost-of-illness during 2013 was estimated from a societal perspective among patients diagnosed between 1987 and 2013.

Results: Among 358 patients with acromegaly ( $48 \%$ men, mean age at diagnosis 50.0 (s.D. 15.3) years) at least one comorbidity was reported in $81 \%(n=290)$. The most common comorbidities were hypertension $(40 \%, n=142)$, neoplasms outside the pituitary $(30 \%, n=109)$, hypopituitarism $(22 \%, n=80)$ and diabetes mellitus $(17 \%, n=61)$. Acromegaly treatment was initiated on average 3.7 (s.D. 6.9) months after diagnosis. Among the 301 treated patients, the most common first-line treatments were surgery $(60 \%, n=180)$, somatostatin analogues $(21 \%, n=64)$ and dopamine agonists $(14 \%, n=41)$. After primary surgery, $24 \%(n=44)$ received somatostatin analogues. The annual perpatient cost was $€ 12000$; this was $€ 8700$ and $€ 16000$ if diagnosed before or after July 2005, respectively. The cost-ofillness for acromegaly and its comorbidities was $77 \%$ from direct costs and $23 \%$ from production loss.

Conclusions: The prevalence of comorbidity is high in patients with acromegaly. The most common first-line treatment in acromegalic patients was surgery followed by somatostatin analogues. The annual per-patient cost of acromegaly and its comorbidities was $€ 12000$.
\end{abstract}

\section{Introduction}

Acromegaly has a prevalence of at least 60 per million and an incidence of 3-5 cases per million per year $(1,2)$. It is most commonly caused by increased growth hormone (GH) secretion from a benign pituitary adenoma (3). The disease is associated with comorbidities affecting e.g. the cardiovascular system, the musculoskeletal organs, the respiratory system,
() 2017 European Society of Endocrinology Printed in Great Britain and the endocrine/metabolic system $(4,5,6)$, as well as an increased mortality, mainly from cardiovascular diseases $(5,6,7,8)$. Acromegaly and its associated comorbidities are associated with reduced quality of life $(9,10,11,12)$. Increased GH secretion leads to increased serum insulin-like growth factor I (IGF1) concentration, insulin resistance, growth of skin, connective tissue,

Published by Bioscientifica Ltd. 
cartilage, bone, organs, and other tissues in the body. A somatotrope pituitary adenoma can also cause local symptoms with hypopituitarism and visual field defects. The disease has an insidious onset and therefore, the delay to diagnosis is often substantial, 3-7 years from onset of symptoms $(5,13,14,15)$.

The goal of therapy is to normalize the circulating levels of GH and IGF1 $(3,16)$ and thereby reduce comorbidities and normalize the excess mortality $(5,6)$. Treatment options include surgery, pharmacotherapy and radiation therapy, with transsphenoidal pituitary surgery being the recommended first-line treatment (17, 18). Pharmacotherapy consists of somatostatin analogues (SSA), e.g. lanreotide and octreotide, but can also include a growth hormone receptor antagonist (GHRA), in the form of pegvisomant, or dopamine agonists (DA), e.g. cabergoline $(16,17)$. Radiation therapy is an alternative in patients with uncontrolled acromegaly who have failed surgical and medical therapies or when these options are unsuitable (17). The development of stereotactic radiosurgery may have improved the benefit-risk ratio of radiotherapy, but the main drawback of radiation therapy is the extended time delay (years) between treatment administration and disease remission as well as concerns over long-term safety due to the risk of hypopituitarism, stroke and secondary malignancies (19).

The objective of this study was to describe comorbidities and treatment patterns among patients with acromegaly, and to estimate the cost-of-illness of acromegaly in Sweden from a societal perspective.

\section{Subjects and methods}

The study consisted of two parts: a longitudinal study of treatment patterns and a prevalence-based cost-of-illness study measured from a societal perspective.

Data were obtained via linkage of several national registers which cover the entire Swedish population. Patients were identified in the National Patient Register, which includes information on all specialized health care contacts. Via the unique personal identification number, this dataset was linked to the Swedish Prescribed Drug Register, including data on all prescribed medicines purchased in Swedish pharmacies (since July 2005); the Cause of Death Register for data on time and cause of death; and the Register on Sickness Absence, including data on time and underlying diagnosis for sickness absence periods lasting $>14$ days. The registers are held by the National Board of Health and Welfare, and the Social Insurance Agency.

\section{Eligibility criteria}

The part focusing on treatment patterns included all adult patients ( $>18$ years of age at acromegaly diagnosis) with a first acromegaly diagnosis due to a pituitary adenoma between 1 July 2005 and 31 December 2013 (the inclusion period started in July 2005 since this is the earliest time point for when data from the Swedish Prescribed Drug Register is available). Acromegaly diagnosis was defined as International Statistical Classification of Diseases and Related Health Problems-10th Revision (ICD-10) code E22.0 (acromegaly) and at least one of the ICD-10 codes D35.2 or D44.3 (neoplasm of pituitary gland), where the neoplasm diagnosis occurred up to 5 years before the first acromegaly diagnosis or any time after the acromegaly diagnosis until end of study (31 December $2013) ;$ i.e. both the acromegaly diagnosis and one of the neoplasm diagnoses were required. Patients with a specialized health care contact for acromegaly from 1 January 1987 to 1 July 2005 were excluded in order to exclude patients diagnosed with acromegaly before July 2005. Patients were categorized into subgroups based on time of diagnosis (first specialized health care contact for acromegaly (ICD-10 code E22.0) before 1 January 2010 vs on or after 1 January 2010).

The second part of the study focused on the costof-illness among all adult patients diagnosed with acromegaly due to a pituitary adenoma in Sweden between 1 January 1987 and 31 December 2013. The diagnostic criteria were similar to those described above: Acromegaly diagnosis was defined as ICD-10/ICD-9 code E22.0/253A with ICD-10/ICD-9 code D35.2/237A or D44.3/227D, where the neoplasm diagnosis occurred up to 5 years before the first acromegaly diagnosis or any time after diagnosis until end of study (31 December 2013); i.e. both the acromegaly diagnosis and one of the neoplasm diagnoses were required for this population as well. To avoid overestimating the costs of acromegaly and its comorbidities, patients with no specialized health care contact due to acromegaly during 2013 were not included in the study population. Patients were categorized into subgroups based on the time of their diagnosis (first specialized health care contact for acromegaly (ICD-10/ ICD-9 code E22.0/253A) before 1 July 2005 vs on or after 1 July 2005). 
Subgroups based on time of diagnosis were formed in order to study treatment patterns and cost-of-illness over time. The cut-offs were decided a priori and they divided each population into similarly sized subgroups.

\section{Comorbidities}

All ICD codes registered at specialized health care visits for the patient population were reviewed and those considered related to acromegalic comorbidities were included if they were registered on or after the date of acromegaly diagnosis. The diagnostic codes for the comorbidities are listed in the Supplementary Table 1

Table 1 Patient characteristics and comorbidities among patients with acromegaly in Sweden.

\begin{tabular}{|c|c|c|}
\hline & $\begin{array}{l}\text { Treatment } \\
\text { patterns } \\
\text { population } \\
(n=358)\end{array}$ & $\begin{array}{c}\text { Cost-of-illness } \\
\text { population } \\
(n=529)\end{array}$ \\
\hline $\begin{array}{l}\text { Age at diagnosis (years), } \\
\text { mean (s.D.) }\end{array}$ & $50.0(15.3)$ & $49.0(12.8)$ \\
\hline \multicolumn{3}{|l|}{ Sex, $n(\%)$} \\
\hline Male & $170(47.5 \%)$ & $253(47.8 \%)$ \\
\hline Female & $188(52.5 \%)$ & $276(52.2 \%)$ \\
\hline \multicolumn{3}{|l|}{ Time of diagnosis, $n(\%)$} \\
\hline Before 2010 & $186(52.0)$ & $\mathrm{n} / \mathrm{a}$ \\
\hline On or after 2010 & $172(48.0)$ & $\mathrm{n} / \mathrm{a}$ \\
\hline Before July 2005 & $\mathrm{n} / \mathrm{a}$ & $294(55.6)$ \\
\hline On or after July 2005 & $\mathrm{n} / \mathrm{a}$ & $235(44.4)$ \\
\hline \multicolumn{3}{|l|}{ Comorbidities, $n(\%)$} \\
\hline Any complication/comorbidity & $290(81.0 \%)$ & $475(89.8 \%)$ \\
\hline Hypertension & $142(39.7 \%)$ & $257(48.6 \%)$ \\
\hline $\begin{array}{l}\text { Neoplasms (excl. pituitary } \\
\text { adenomas) }\end{array}$ & $109(30.4 \%)$ & $231(43.7 \%)$ \\
\hline Hypopituitarism & $80(22.3 \%)$ & $151(28.5 \%)$ \\
\hline Diabetes mellitus & $61(17.0 \%)$ & $93(17.6 \%)$ \\
\hline Arthropathy & $52(14.5 \%)$ & $174(32.9 \%)$ \\
\hline Sleep disorders & $50(14.0 \%)$ & $97(18.3 \%)$ \\
\hline Visual field defects & $39(10.9 \%)$ & $42(7.9 \%)$ \\
\hline Arrhythmia & $35(9.8 \%)$ & $84(15.9 \%)$ \\
\hline Mental disorder/depression & $30(8.4 \%)$ & $50(9.5 \%)$ \\
\hline Heart failure & $22(6.1 \%)$ & $36(6.8 \%)$ \\
\hline Teeth and jaws & $19(5.3 \%)$ & $38(7.2 \%)$ \\
\hline Abnormal menstruation & $17(4.7 \%)$ & $36(6.8 \%)$ \\
\hline Headache & $17(4.7 \%)$ & $34(6.4 \%)$ \\
\hline Ischaemic heart disease & $15(4.2 \%)$ & $39(7.4 \%)$ \\
\hline Osteoporosis & $13(3.6 \%)$ & $19(3.6 \%)$ \\
\hline Valvular disease & $12(3.4 \%)$ & $28(5.3 \%)$ \\
\hline Cholelithiasis & $10(2.8 \%)$ & $54(10.2 \%)$ \\
\hline Nasal polyps & $9(2.5 \%)$ & $15(2.8 \%)$ \\
\hline Stroke & $9(2.5 \%)$ & $29(5.5 \%)$ \\
\hline Arterial and capillary disease & $6(1.7 \%)$ & $20(3.8 \%)$ \\
\hline Carpal tunnel syndrome & $5(1.4 \%)$ & $19(3.6 \%)$ \\
\hline Colon polyps & $5(1.4 \%)$ & $16(3.0 \%)$ \\
\hline Epilepsy & $n<5$ & $10(1.9 \%)$ \\
\hline Embolism & $n<5$ & $9(1.7 \%)$ \\
\hline
\end{tabular}

(see section on supplementary data given at the end of this article), and the total frequencies of comorbidities are presented in Table 1.

\section{Treatment patterns}

The following treatment options for acromegaly were included: surgery, radiation therapy, SSA, DA and GHRA. The start of treatment was defined as the date of the surgery or radiation therapy, or as the first purchase of the drug. The diagnostic codes for the treatments are listed in the Supplementary Table 2.

\section{Cost-of-illness}

The cost-of-illness assessment encompassed direct medical costs (health care resource use and prescription drugs), direct non-medical costs (transportation in connection with health care visits), and production loss (due to sickness absence or mortality) arising due to acromegaly or its comorbidities, respectively, in Sweden during 1 January to 31 December 2013. All ICD-10 codes; procedure codes for surgical, medical or diagnostic interventions; and Anatomical Therapeutic Chemical (ATC) codes for prescription drugs, registered during 2013 were reviewed for inclusion. All included codes were attributed to either acromegaly or its comorbidities.

Data on health care use were retrieved from the National Patient Register, and the costs were estimated based on the Diagnosis Related Group (DRG) codes which are registered for each health care visit. The DRG code reflects the costs associated with the health care visit and any intervention performed at that occasion. The costs for prescription drugs were retrieved from the Swedish Prescribed Drug Register, and included both patient co-payment and the reimbursed cost. The costs for transportation in connection with health care visits were derived from a previous Swedish publication (20). The costs of lost productivity encompassed sickness absence and mortality from acromegaly and its comorbidities among patients aged $<65$ years (i.e. the standard Swedish retirement age). Only sickness absence periods lasting $>14$ days are reported in the Register on Sickness Absence (thus, shorter sickness absence periods were not captured). To correctly calculate the lost productivity, the initial 14 days were added to each absence period. Production loss due to mortality was estimated from the deaths in 2013. The costs were estimated until the point in time when the patient would have reached 65 years, in order 
to balance the lack of data on production loss in 2013 due to deaths occurring prior to 2013. The costs occurring after 2013 were discounted at a rate of 3\% per annum. The costs for lost productivity were measured with the human capital approach based on average national wages and social security contributions $(21,22)$. All costs were adjusted to 2014 levels using the consumer price index, and presented in € (average exchange rate 2014: $1 €=9.10 \mathrm{SEK})$, rounded to the nearest hundred.

\section{Statistical analysis}

Continuous variables were described with mean and standard deviation (s.D.). Categorical variables were described with frequency and percentage. For selected subgroup analyses, 95\% confidence intervals (CI) are presented. Percentages were based on the number of nonmissing observations. Analyses were performed in SAS version 9.4 (Cary, NC, USA).

\section{Ethical considerations}

The study was approved by the Regional Ethical Review Board at the University of Gothenburg (820-14). For ethical reasons, the number of patients was presented as ' $<5$ ' when the exact number of patients was $1-4$, so that no individual could be identified.

\section{Results}

\section{Treatment patterns}

The predefined selection criteria identified 358 patients (men $48 \%$, women $52 \%$ ) with a first diagnosis of acromegaly due to a pituitary adenoma between 1 July 2005 and 31 December 2013. The mean (s.D.) follow-up time from the diagnosis until death or until 31 December 2013 was 4.2 (2.5) years (Table 1). Mean age at diagnosis was
50.0 (s.D. 15.3) years. At least one comorbidity was found in 290 patients $(81 \%)$. The most common comorbidities were hypertension (40\%), neoplasms outside the pituitary gland (30\%), hypopituitarism (22\%) and diabetes mellitus (17\%). In descending order, the most common neoplasms (outside the pituitary gland, i.e. excluding D35.2 and D44.3) were benign neoplasms in the brain and other parts of central nervous system (ICD-10 D33.X, 5\% of patients), benign neoplasm of other and unspecified endocrine glands (D35.X (except D35.2), 4\%), other malignant neoplasms of skin (C44.X, 4\%), melanocytic naevi (D22.X, 4\%) and neoplasm of uncertain or unknown behaviour of oral cavity and digestive organs (D37.X, 3\%). The overall occurrence of comorbidities was higher among the 186 patients diagnosed before 2010 (88\% (CI 84-93\%)) than among the 172 patients diagnosed on or after 2010 (73\% (CI 67-80\%)).

Out of all 358 patients, $66 \%(n=235)$ had undergone surgery for acromegaly at any time during the observation period, with $37 \% \quad(n=86)$ of those patients having undergone surgery more than once. Radiation therapy had been performed in 43 patients (12\%); 16\% (CI 11-21\%) among those diagnosed before 2010 and $8 \%$ (CI $4-12 \%)$ among those diagnosed on or after 2010. Onethird $(n=127,36 \%)$ had been treated with SSA; this was $44 \%$ ( $n=81$, CI $36-51 \%)$ among those diagnosed before 2010 and $27 \%$ ( $n=46$, CI 20-33\%) among those diagnosed on or after 2010 . Octreotide had been used by 57 patients ( $45 \%$ of the 127 patients), lanreotide by 36 patients (28\%), and 32 patients had used both during the follow-up period (SSA type was unknown for the remaining 2 patients). DA had been used by 72 patients (20\%), and overall $34(10 \%)$ had been treated with GHRA.

The first-line acromegaly treatment was initiated on average 3.7 (CI 2.9-4.4) months after diagnosis (Table 2). The most common first-line treatments were surgery (60\%), SSA (21\%) and DA (14\%). In 16\% of the patients, no acromegaly treatment was recorded during the follow-up.

Table 2 Type of and time to first-line treatment among patients with acromegaly receiving any type of treatment.

\begin{tabular}{|c|c|c|c|}
\hline & $\begin{array}{l}\text { Total treatment patterns population } \\
\qquad(n=301)\end{array}$ & $\begin{array}{l}\text { Subgroup diagnosed before } 2010 \\
\qquad(n=161)\end{array}$ & $\begin{array}{l}\text { Subgroup diagnosed on } \\
\text { or after } 2010(n=140)\end{array}$ \\
\hline \multicolumn{4}{|c|}{ Type of first-line treatment, $n(\%)$} \\
\hline Surgery & $180(59.8 \%)$ & $93(57.8 \%)$ & $87(62.1 \%)$ \\
\hline SSA (alone) & $64(21.3 \%)$ & $37(23.0 \%)$ & $27(19.3 \%)$ \\
\hline DA (alone) & $41(13.6 \%)$ & $23(14.3 \%)$ & $18(12.9 \%)$ \\
\hline Other & $16(5.3 \%)$ & $8(5.0 \%)$ & $8(5.7 \%)$ \\
\hline $\begin{array}{l}\text { Time to first-line treatment } \\
\text { (months), mean }(95 \% \mathrm{Cl})\end{array}$ & $3.7(2.9-4.4)$ & $4.3(2.9-5.7)$ & $3.0(2.4-3.5)$ \\
\hline
\end{tabular}

GHRA was given as first-line treatment for $<5$ patients and is included in 'other'. 57 patients received no treatment, 25 diagnosed before 2010 and 32 diagnosed on or after 2010.

95\% Cl, 95\% confidence interval; DA, dopamine agonist; GHRA, growth hormone receptor antagonist; SSA, somatostatin analogue. 
Table 3 Type of and time to second-line treatment by type of first line-treatment in patients with acromegaly.

\begin{tabular}{|c|c|c|c|c|c|c|}
\hline \multirow[b]{2}{*}{$\begin{array}{l}\text { First-line/second-line } \\
\text { treatment }\end{array}$} & \multicolumn{2}{|c|}{$\begin{array}{c}\text { Total treatment patterns } \\
\text { population }\end{array}$} & \multicolumn{2}{|c|}{$\begin{array}{c}\text { Subgroup diagnosed } \\
\text { before } 2010\end{array}$} & \multicolumn{2}{|c|}{$\begin{array}{l}\text { Subgroup diagnosed on or after } \\
2010 \\
\end{array}$} \\
\hline & $n(\%)$ & $\begin{array}{l}\text { Time to second-line, } \\
\text { (months), mean } \\
(95 \% \mathrm{Cl})\end{array}$ & $n(\%)$ & $\begin{array}{l}\text { Time to second-line, } \\
\text { (months), mean } \\
(95 \% \mathrm{Cl})\end{array}$ & $n(\%)$ & $\begin{array}{l}\text { Time to second-line, } \\
\text { (months), mean } \\
(95 \% \mathrm{Cl})\end{array}$ \\
\hline $\begin{array}{l}\text { First-line: Surgery } \\
\text { Second-line: }\end{array}$ & 180 & & 93 & & 87 & \\
\hline Any second-line treatment & $67(37.2 \%)$ & $15.2(11.5-18.8)$ & $46(49.5 \%)$ & $18.5(13.6-23.5)$ & $21(24.1 \%)$ & $7.9(5.6-10.1)$ \\
\hline SSA & $44(24.4 \%)$ & $14.0(9.5-18.4)$ & $31(33.3 \%)$ & $17.3(11.3-23.3)$ & $13(14.9 \%)$ & $6.0(3.6-8.4)$ \\
\hline Radiation & $15(8.3 \%)$ & $15.0(9.2-20.7)$ & $10(10.8 \%)$ & $17.1(8.7-25.5)$ & $5(5.7 \%)$ & $10.7(3.6-17.8)$ \\
\hline $\mathrm{DA}$ & $5(2.8 \%)$ & $27.8(-5.5$ to 61.2$)$ & $n<5$ & $\mathrm{n} / \mathrm{a}$ & $<5$ & $\mathrm{n} / \mathrm{a}$ \\
\hline Other & $n<5$ & $\mathrm{n} / \mathrm{a}$ & $n<5$ & $\mathrm{n} / \mathrm{a}$ & $<5$ & $\mathrm{n} / \mathrm{a}$ \\
\hline No second-line treatment & $113(62.8 \%)$ & $\mathrm{n} / \mathrm{a}$ & $47(50.5 \%)$ & $\mathrm{n} / \mathrm{a}$ & $66(75.9 \%)$ & $\mathrm{n} / \mathrm{a}$ \\
\hline $\begin{array}{l}\text { First-line: SSA } \\
\text { Second-line: }\end{array}$ & 64 & & 37 & & 27 & \\
\hline Any second-line treatment & $47(73.4 \%)$ & $6.3(4.4-8.3)$ & $32(86.5 \%)$ & $6.8(4.2-9.3)$ & $15(55.6 \%)$ & $5.4(2.2-8.6)$ \\
\hline Surgery & $37(57.8 \%)$ & $5.3(3.4-7.1)$ & $27(73.0 \%)$ & $5.5(3.4-7.5)$ & $10(37.0 \%)$ & $4.7(0.2-9.1)$ \\
\hline Other & $10(15.6 \%)$ & $\mathrm{n} / \mathrm{a}$ & $5(13.5 \%)$ & $\mathrm{n} / \mathrm{a}$ & $5(18.5 \%)$ & $\mathrm{n} / \mathrm{a}$ \\
\hline No second-line treatment & $17(26.6 \%)$ & $\mathrm{n} / \mathrm{a}$ & $5(13.5 \%)$ & $\mathrm{n} / \mathrm{a}$ & $12(44.4 \%)$ & $\mathrm{n} / \mathrm{a}$ \\
\hline $\begin{array}{l}\text { First-line: DA } \\
\text { Second-line: }\end{array}$ & 41 & & 23 & & 18 & \\
\hline Any second-line treatment & $15(36.6 \%)$ & $7.8(0.2-15.4)$ & $8(34.8 \%)$ & $12.0(-3.0$ to 26.9$)$ & $7(38.9 \%)$ & $2.9(-0.8$ to 6.7$)$ \\
\hline Surgery & $13(31.7 \%)$ & $8.5(-0.4$ to 17.4$)$ & $6(26.1 \%)$ & $15.0(-6.0$ to 36.0$)$ & $7(38.9 \%)$ & $2.9(-0.8$ to 6.7$)$ \\
\hline Other & $n<5$ & $\mathrm{n} / \mathrm{a}$ & $n<5$ & $\mathrm{n} / \mathrm{a}$ & 0 & $\mathrm{n} / \mathrm{a}$ \\
\hline No second-line treatment & $26(63.4 \%)$ & $\mathrm{n} / \mathrm{a}$ & $15(65.2 \%)$ & $\mathrm{n} / \mathrm{a}$ & $11(61.1 \%)$ & $\mathrm{n} / \mathrm{a}$ \\
\hline
\end{tabular}

$95 \% \mathrm{Cl}, 95 \%$ confidence interval; DA, dopamine agonist; SSA, somatostatin analogue.

Of the 180 patients who received surgery as firstline treatment, no additional therapy was recorded for $63 \%$ during follow-up, while $24 \%$ received SSA that was initiated on average 14.0 (CI 9.5-18.4) months after surgery (Table 3 ). The most common second-line treatment after primary treatment with SSA was surgery (58\%), which was performed on average 5.3 (CI 3.4-7.1) months after the initiation of SSA treatment. In 17 patients (27\%), no further treatment was recorded when SSA was the first-line treatment. The most common treatment after first-line DA treatment was surgery (32\%), while in the majority (63\%), no further treatment was recorded.

When assessing treatment patterns by time of diagnosis, the findings suggested that time to first-line as well as to second-line treatment was shorter for those diagnosed on or after 2010 (Tables 2 and 3).

\section{Cost-of-illness}

This part of the study included 529 patients who had used specialized health care due to acromegaly during 2013 (Table 1). In total, $90 \%$ had at least one comorbidity; the most common comorbidities were hypertension (49\%), neoplasms outside the pituitary gland (44\%), arthropathy (33\%) and hypopituitarism (29\%). The overall occurrence of comorbidities was higher among the 294 patients diagnosed before July 2005 (96\% (CI 94-98\%)) than among the 235 patients diagnosed on or after July 2005 $(82 \%$ (CI 77-87\%)). In these subgroups, the percentages of patients aged 65 years or older on 1 January 2013 were 51\% (CI $45-57 \%$ ) vs 22\% (CI 17-27\%), respectively.

The direct medical costs, direct non-medical costs and costs of production loss due to acromegaly and its comorbidities during year 2013 in Sweden was €6 328000 , which corresponds to an average cost of $€ 12000$ per patient (Table 4). The direct medical costs constituted the largest proportion of the total cost (77\%), while the costs from lost productivity amounted to $23 \%$.

Overall, costs due to acromegaly constituted $75 \%$ of the total cost with the remaining $25 \%$ being attributed to comorbidities. Acromegaly drug costs constituted $48 \%$ of the total costs, while health care resource use due to acromegaly was $16 \%$. The costs of production loss from both sickness absence and death was $€ 661000$ for acromegaly and €787 000 for comorbidities, estimated among the patients aged $<65$ years $(n=327$ on 1 January 2013). 
Table 4 The total number of resources used, the total cost, and the total cost per patient due to acromegaly and its comorbidities during 2013 in Sweden. All costs rounded to the nearest hundred.

\begin{tabular}{|c|c|c|c|}
\hline & Total number & Total cost $(€)$ & Cost per patient $(€)$ \\
\hline \multirow{2}{*}{\multicolumn{4}{|c|}{$\begin{array}{l}\text { Direct medical costs } \\
\text { Acromegaly }\end{array}$}} \\
\hline & & & \\
\hline Health care resources (number of encounters) & 856 & 985800 & 1900 \\
\hline Outpatient & 632 & 248600 & 500 \\
\hline Inpatient & 20 & 51200 & 100 \\
\hline Surgical interventions & 37 & 387000 & 700 \\
\hline Medical interventions & 167 & 299100 & 600 \\
\hline Drugs (number of purchases) & 1189 & 3064500 & 5800 \\
\hline SSA & 765 & 1891900 & 3600 \\
\hline DA & 246 & 8200 & 0 \\
\hline GHRA & 178 & 1164400 & 2200 \\
\hline \multicolumn{4}{|l|}{ Comorbidities } \\
\hline Health care resources (number of encounters) & 113 & 378000 & 700 \\
\hline Outpatient & 41 & 15700 & 0 \\
\hline Inpatient & 14 & 52300 & 100 \\
\hline Interventions & 58 & 309900 & 600 \\
\hline Drugs (number of purchases) & 497 & 420900 & 800 \\
\hline Direct non-medical costs & & 31000 & 100 \\
\hline Acromegaly (number of occasions) & 856 & 27500 & 100 \\
\hline Comorbidities (number of occasions) & 113 & 3600 & 0 \\
\hline Productivity loss & & 1448000 & 2700 \\
\hline \multicolumn{4}{|l|}{ Acromegaly } \\
\hline Sickness absence (number of days) & 2738 & 408200 & 800 \\
\hline Mortality & $\mathrm{n} / \mathrm{a}$ & 253000 & 500 \\
\hline \multicolumn{4}{|l|}{ Comorbidities } \\
\hline Sickness absence (number of days) & 3579 & 533600 & 1000 \\
\hline Mortality & $\mathrm{n} / \mathrm{a}$ & 253000 & 500 \\
\hline Total cost & & 6328000 & 12000 \\
\hline
\end{tabular}

There were 2738 days of sickness absence due to acromegaly (among a total of 32 patients) and 3579 sickness absence days due to comorbidities (28 patients).

The distribution of the direct medical costs (i.e. for health care resource use and drugs) is presented in Fig. 1. Drugs for acromegaly and comorbidities constituted more than two-thirds of the total direct medical costs. Overall, 140 patients had purchased SSA during 2013 (average cost $€ 13500$ per patient with at least one such purchase), 45 had purchased DA (€200 per patient) and 42 had purchased GHRA (€27 700 per patient). The medical interventions for acromegaly encompassed for example imaging, laboratory evaluations and neuro-ophthalmological assessments.

The total cost per patient was lower if diagnosed before July 2005 (€8700 (CI: €6500-€10900)) than if diagnosed on or after July 2005 (€16000 (CI: €12800$€ 19300)$ ). Figure 2 presents the distribution of the costs in these two subgroups. The percentage of the total costs that was attributed to the comorbidities was 38\% if diagnosed before July 2005 and 16\% if diagnosed more recently. The most pronounced discrepancy was observed for costs related to acromegaly, particularly health care resource use (€400 (5\% of the total cost) vs $€ 3700$ (23\%)), sickness absence (€100 (1\%) vs €1600 (10\%)), and production loss due to mortality (no cost vs $€ 1100$ (7\%)) for patients diagnosed before and after 2005, respectively.

As described above, a higher percentage of patients diagnosed before 2005 were aged 65 years or older in 2013; 51\% vs 22\% among patients diagnosed after 2005 . The total cost per patient was lower among those aged 65 years and older than among the younger patients, both among patients diagnosed before 2005 (€6000 vs €11 500) and among those diagnosed after 2005 (€9900 vs €17 800). Over all ages, the direct medical costs were summarized to $€ 6900$ per patient diagnosed before 2005 and to $€ 12000$ if diagnosed after 2005. However, there were no substantial age differences in the direct medical costs among patients diagnosed before 2005 ( $€ 6000$ for patients aged $\geq 65$ years vs $€ 7900$ for patients aged $<65$ years), nor among those diagnosed after 2005 (€9700 vs €12700). The older patients had no indirect costs, since these could arise only among patients aged $<65$ years. 


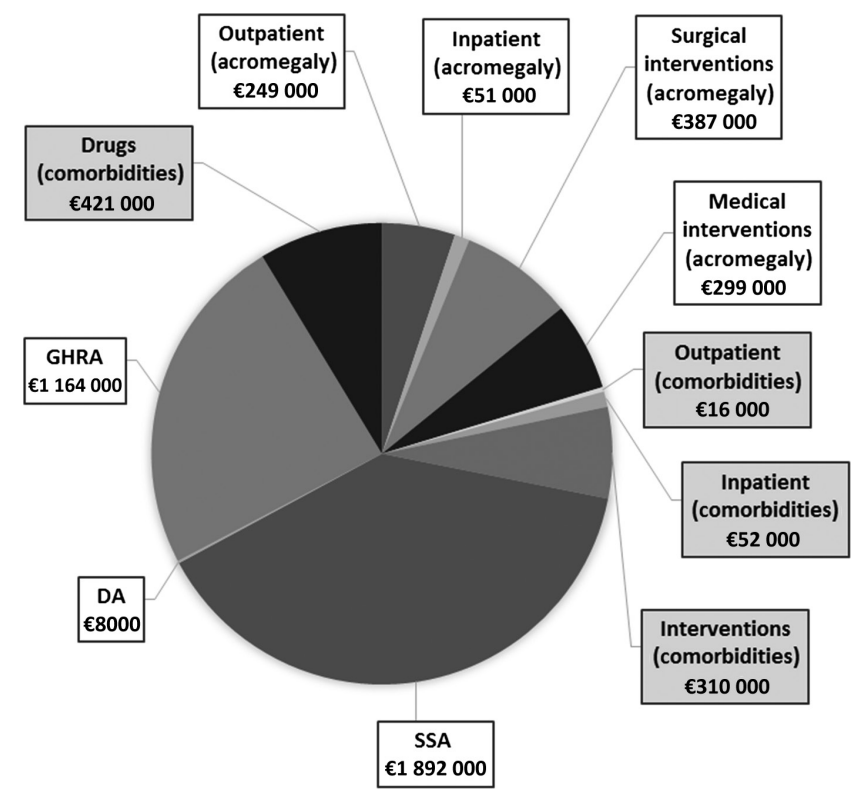

Figure 1

Distribution of the total direct medical costs (i.e. health care resource use and drugs) due to acromegaly and its comorbidities during 2013 in Sweden. DA, dopamine agonist; GHRA, growth hormone receptor antagonist; SSA, somatostatin analogue. All costs rounded to the nearest thousand.

For all patients included in the cost-of-illness analysis, the mean total cost per patient due to acromegaly was $€ 9100$ while the mean total cost per patient due to comorbidities was $€ 3000$. The corresponding numbers for those diagnosed before July 2005 were $€ 5400$ and $€ 3300$, while for those diagnosed after July 2005 the costs due to acromegaly and comorbidities were $€ 13500$ and $€ 2600$ respectively.

\section{Discussion}

In this study, the occurrence of comorbidities and longitudinal treatment patterns were described among patients with acromegaly in Sweden. Furthermore, the annual economic burden of acromegaly and its comorbidities to society was estimated in Sweden.

The majority of patients (81\%) diagnosed with acromegaly due to a pituitary adenoma between 2005 and 2013 had at least one comorbidity. The most common comorbidities were hypertension, neoplasms (outside the pituitary gland), hypopituitarism and diabetes mellitus. The observed frequency of neoplasms gave no clear indication of a deviating pattern, although no comparison to the general population was made. The clinical characteristics in this population were similar to those previously described in other cohorts of patients with acromegaly $(4,10,23,24)$, supporting the validity of the applied eligibility criteria. A higher percentage of patients diagnosed prior to 2010 as compared to after 2010 had at least one comorbidity. Likely explanations are that the more recently diagnosed patients have not yet developed comorbidities to the same extent as those who have had acromegaly during a longer period of time, the shorter delay in diagnosis in more recently diagnosed patients, and possibly the fact that radiation therapy was more commonly used before $2010(25,26,27,28)$.

Surgical treatment is the recommended primary treatment for patients with acromegaly (17). In our study population, two-thirds had received surgical treatment, which is in alignment with other reports $(25,26,27$, $28)$. The majority who had a primary surgical treatment received no further treatment suggesting that a large proportion of patients obtained biochemical remission by surgery. One-quarter of the patients received SSA as the second-line treatment after surgery. Radiation therapy was administered in $8 \%$ of the patients who received surgery as the first-line treatment, and overall $12 \%$ of the patients received radiation therapy ( $16 \%$ of those diagnosed before 2010 vs $8 \%$ of those diagnosed on or after 2010). A similar decline in use of radiation therapy was also seen in studies performed in Belgium (25), Canada (28), Germany (26) and Spain (27). The decline observed in our study could also have been influenced by the longer follow-up time among those diagnosed before 2010, but a more likely explanation is a change in treatment practices over time, as seen in other studies $(25,26,27,28)$. This is in

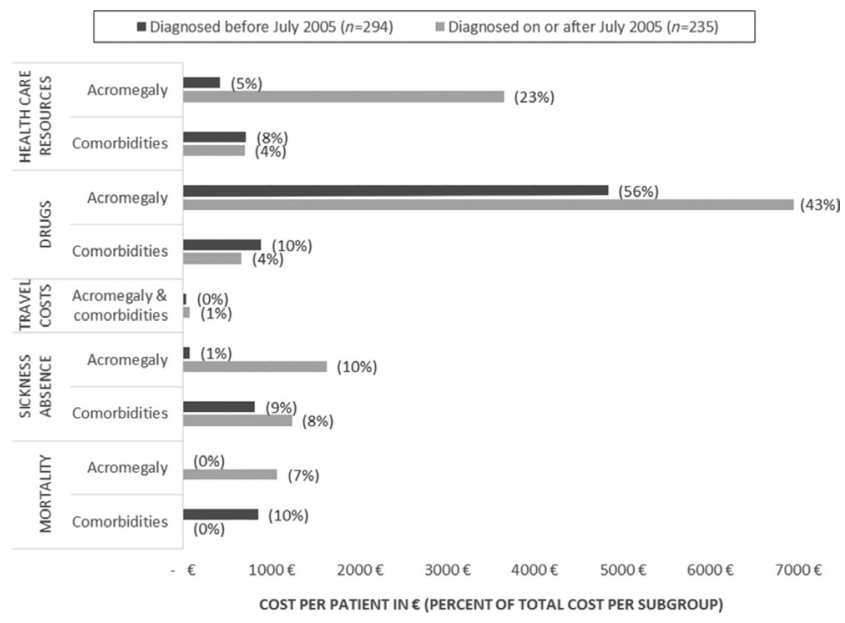

Figure 2

Distribution of total costs due to acromegaly and its comorbidities during 2013 in Sweden, stratified by time of diagnosis. 
accordance with treatment guidelines (published 2014) stating that radiation therapy is only recommended in case of residual tumour mass after surgery and if medical therapy is unavailable, unsuccessful or not tolerated (17).

The second most common first-line treatment was SSA, received by $21 \%$ of the patients. SSA was typically followed by surgery, which was performed on average 5 months after SSA initiation. This treatment pattern could indicate that SSA treatment was used for the purpose of improving the surgical outcome as has been suggested in some previous studies (29). Another interesting observation was that the frequency of SSA treatment was higher in patients diagnosed before 2010. There are a number of possible explanations, including a shorter follow-up time among those diagnosed on or after 2010 or an improvement in the surgical outcome. In $16 \%$ of the patients, no treatment for acromegaly was recorded during follow-up. Most of these patients had been diagnosed with acromegaly in the end of 2012 or in 2013, and it is therefore possible that a therapeutic intervention did not occur before the end of this study. Another possibility is that some patients had mild disease, refused treatment or had comorbidities affecting the decision of treatment.

The findings suggested that the time to first treatment was shorter among those with a more recent diagnosis of acromegaly. This could suggest a trend towards a more prompt initiation of treatment once the patient has been diagnosed with acromegaly. However, the pattern may again have been influenced by the shorter follow-up time among those diagnosed on or after 2010. Another plausible explanation is an increased awareness of the complications and comorbidities associated with acromegaly as well as the more solid data on the importance of biochemical control for mortality in these patients that has shortened the time from diagnosis to treatment $(5,6)$.

The societal cost-of-illness of acromegaly and its comorbidities was assessed among 529 patients, which is to our knowledge the largest such investigation that has been performed. The economic burden of acromegaly and its comorbidities was estimated to $€ 6328000$ in year 2013, corresponding to an annual per-patient cost of $€ 12000$. The direct costs made up the majority of the total cost, while the production loss only constituted a smaller part. The largest driver of the direct medical costs was drugs for the treatment of acromegaly, followed by health care resource use due to acromegaly, drugs for comorbidities, and lastly health care resource use due to comorbidities. Production loss from sickness absence due to comorbidities was the largest driver of the indirect costs, followed by sickness absence due to acromegaly.
A gradient was observed for the costs in relation to the time of diagnosis. The annual per-patient cost was markedly higher for patients diagnosed on or after July 2005 compared to before. This could be explained by a more active resource use closer to the diagnosis of acromegaly. Indeed, a large contributor to this gradient was the difference in direct medical costs, which were summarized to $€ 6900$ per patient diagnosed before July 2005 and to $€ 12000$ per patient diagnosed on or after July 2005. Comorbidities gave rise to a larger proportion of the total costs among patients diagnosed before July 2005 than among those diagnosed more recently (38\% vs $16 \%)$; thus, the costs related to acromegaly constituted a larger proportion of the total cost among those diagnosed more recently. One explanation for this difference in distribution of costs could be that the more recently diagnosed patients had not yet developed comorbidities to the same extent as those who have had acromegaly for a longer period of time (comorbidities were present in $96 \%$ of those diagnosed before July 2005 as compared to $82 \%$ in those diagnosed on or after July 2005, and the patients diagnosed before July 2005 were older at the time of the cost-of-illness assessment). Another potential explanation could be that the shorter delay of diagnosis and improved surgical techniques and medical therapy have decreased the development of comorbidities.

There are a few previous studies of the costs associated with acromegaly $(30,31)$. However, comparisons of costof-illness estimates are sensitive to differences in e.g. health care systems between countries, the perspective in which the costs are estimated e.g. from a societal or health care perspective, the methods applied to assess resources and costs, etc. In relation to our findings of an annual per-patient cost of $€ 12000$, previous Swedish studies have estimated the societal per-patient cost of diabetes (type 1 and 2) to about $€ 3600$ per year (32), of atrial fibrillation to about $€ 5000$ per year (33), of asthma to about $€ 1800$ per year (34), and the costs of breast and prostate cancer (including also e.g. informal care) to be €55400 and $€ 31500$ per year, respectively (35).

This study was based on real-world data from national registers. All Swedish citizens are covered in the registers and the data are based on clinical practice. Furthermore, the registers have been available for a long period of time, which enabled longitudinal analyses of treatment patterns. Due to the unique personal identification numbers, the linkage between registers is performed with high precision. There are also some limitations. Since the data are based on clinical practice, the diagnostic coding practices may vary between hospitals and/or physicians, etc. The register data 
on health care use included specialized health care only. Some of the comorbidities may be treated in primary care only, and would thus not have been captured in the data. Thus, the occurrence of and cost related to comorbidities could be underestimated. Another consequence is that the costs of primary health care were not included in the cost-of-illness assessment. Finally, we did not validate the search criteria against patient records, however we have in previous studies on craniopharyngioma and pituitary adenoma validated search criteria in Swedish national registries, with good results $(36,37)$. However, by using both the endocrine and the neoplasm diagnosis we have performed a conservative selection of patients. This may have excluded some patients with acromegaly and it has surely excluded the rare patients with acromegaly due to other causes than pituitary adenoma.

\section{Conclusions}

Comorbidity in patients with acromegaly is very frequent. The most common first-line treatment in acromegalic patients was surgery followed by medical treatment with SSA. The annual economic burden of acromegaly and its comorbidities on society in Sweden was estimated to over $€ 6$ million.

\section{Supplementary data}

This is linked to the online version of the paper at http://dx.doi.org/10.1530/ EJE-16-0623.

\section{Declaration of interest}

E L, D G and I B are employed by Nordic Health Economics $A B$, and I $B$ is the owner. Nordic Health Economics $A B$ is a consultancy and research company working with the pharmaceutical and medical device industry as well as with health care organisations and with universities. A H, J D and A B are employed by Ipsen. D S O has been a consultant for Ipsen, Sandoz and Pfizer as well as has received lecture fee from Pfizer. $G J$ has been a consultant for AstraZeneca, Viropharma and Shire, and has received lecture fees from Novo Nordisk, Pfizer, Novartis, Merck Serono and Otsuka.

\section{Funding}

The study was financially supported by Ipsen.

\section{References}

1 Holdaway IM \& Rajasoorya C. Epidemiology of acromegaly. Pituitary 19992 29-41. (doi:10.1023/A:1009965803750)

2 Hoskuldsdottir GT, Fjalldal SB \& Sigurjonsdottir HA. The incidence and prevalence of acromegaly, a nationwide study from 1955 through 2013. Pituitary 201518 803-807. (doi:10.1007/s11102-015-0655-4)

3 Melmed S. Medical progress: acromegaly. New England Journal of Medicine 2006355 2558-2573. (doi:10.1056/NEJMra062453)
4 Colao A, Ferone D, Marzullo P \& Lombardi G. Systemic complications of acromegaly: epidemiology, pathogenesis, and management. Endocrine Reviews 200425 102-152. (doi:10.1210/er.2002-0022)

5 Dekkers OM, Biermasz NR, Pereira AM, Romijn JA \& Vandenbroucke JP. Mortality in acromegaly: a metaanalysis. Journal of Clinical Endocrinology and Metabolism 200893 61-67. (doi:10.1210/ jc.2007-1191)

6 Holdaway IM, Bolland MJ \& Gamble GD. A meta-analysis of the effect of lowering serum levels of GH and IGF-I on mortality in acromegaly. European Journal of Endocrinology 2008159 89-95. (doi:10.1530/EJE08-0267)

7 Bengtsson BA, Eden S, Ernest I, Oden A \& Sjogren B. Epidemiology and long-term survival in acromegaly. A study of 166 cases diagnosed between 1955 and 1984. Acta Medica Scandinavica 1988223 327-335. (doi:10.1111/j.0954-6820.1988.tb15881.x)

8 Sherlock M, Ayuk J, Tomlinson JW, Toogood AA, Aragon-Alonso A, Sheppard MC, Bates AS \& Stewart PM. Mortality in patients with pituitary disease. Endocrine Reviews 201031 301-342. (doi:10.1210/ er.2009-0033)

9 Ben-Shlomo A, Sheppard MC, Stephens JM, Pulgar S \& Melmed S. Clinical, quality of life, and economic value of acromegaly disease control. Pituitary 201114 284-294. (doi:10.1007/s11102-011-0310-7)

10 Biermasz NR, Pereira AM, Smit JW, Romijn JA \& Roelfsema F. Morbidity after long-term remission for acromegaly: persisting jointrelated complaints cause reduced quality of life. Journal of Clinical Endocrinology and Metabolism 200590 2731-2739. (doi:10.1210/ jc.2004-2297)

11 Webb SM \& Badia X. Quality of life in acromegaly. Neuroendocrinology 2015103 106-111. (doi:10.1159/000375451)

12 Crespo I, Santos A, Resmini E, Valassi E, Martinez-Momblan MA $\&$ Webb SM. Improving quality of life in patients with pituitary tumours. US Endocrinology 201410 79-83. (doi:10.17925/ USE.2014.10.01.79)

13 Kreitschmann-Andermahr I, Siegel S, Kleist B, Kohlmann J, Starz D, Buslei R, Koltowska-Haggstrom M, Strasburger CJ \& Buchfelder M. Diagnosis and management of acromegaly: the patient's perspective. Pituitary 201619 268-276. (doi:10.1007/s11102-015-0702-1)

14 Nachtigall L, Delgado A, Swearingen B, Lee H, Zerikly R \& Klibanski A. Changing patterns in diagnosis and therapy of acromegaly over two decades. Journal of Clinical Endocrinology and Metabolism 200893 2035-2041. (doi:10.1210/jc.2007-2149)

15 Drange MR, Fram NR, Herman-Bonert V \& Melmed S. Pituitary tumor registry: a novel clinical resource. Journal of Clinical Endocrinology and Metabolism 200085 168-174. (doi:10.1210/jc.85.1.168)

16 Giustina A, Chanson P, Kleinberg D, Bronstein MD, Clemmons DR, Klibanski A, van der Lely AJ, Strasburger CJ, Lamberts SW, Ho KK et al. Expert consensus document: a consensus on the medical treatment of acromegaly. Nature Reviews Endocrinology 201410 243-248. (doi:10.1038/nrendo.2014.21)

17 Katznelson L, Laws ER Jr, Melmed S, Molitch ME, Murad MH, Utz A, Wass JA \& Endocrine S. Acromegaly: an endocrine society clinical practice guideline. Journal of Clinical Endocrinology and Metabolism 201499 3933-3951. (doi:10.1210/jc.2014-2700)

18 Laws ER \& Jane JA Jr. Neurosurgical approach to treating pituitary adenomas. Growth Hormone and IGF Research 200515 (Supplement A) S36-S41. (doi:10.1016/j.ghir.2005.06.008)

19 Abu Dabrh AM, Asi N, Farah WH, Mohammed K, Wang Z, Farah MH, Prokop LJ, Katznelson L \& Murad MH. Radiotherapy versus radiosurgery in treating patients with acromegaly: a systematic review and meta-analysis. Endocrine Practices 201521 943-956. (doi:10.4158/ EP14574.OR)

20 Bjorholt I, Andersson FL, Kahan T \& Ostergren J. The costeffectiveness of ramipril in the treatment of patients at high risk of cardiovascular events: a Swedish sub-study to the HOPE study. Journal of Internal Medicine 2002251 508-517. (doi:10.1046/j.13652796.2002.00990.x) 
21 Statistics Sweden. Statistikdatabasen: Genomsnittlig grund- och månadslön samt kvinnors lön i procent av mäns lön efter sektor, yrke (SSYK 2012), kön och ålder. År 2014. (Statistical database in Swedish). Accessed on 1 Sep 2015

22 Statistics Sweden. Mer om Arbetskostnadsindex (AKI) (Swedish). (Available at http://www.scb.se/sv_/Hitta-statistik/Statistik-efter-amne/ Arbetsmarknad/Loner-och-arbetskostnader/Arbetskostnadsindexfor-arbetare-och-tjansteman-inom-privat-sektor-AKI/7965/Mer-omArbetskostnadsindex-AKI/). Accessed on 1 Sep 2015.

23 T'Sjoen G, Bex M, Maiter D, Velkeniers B \& Abs R. Health-related quality of life in acromegalic subjects: data from AcroBel, the Belgian registry on acromegaly. European Journal of Endocrinology 2007157 411-417. (doi:10.1530/eje-07-0356)

24 Matta MP, Couture E, Cazals L, Vezzosi D, Bennet A \& Caron P. Impaired quality of life of patients with acromegaly: control of GH/ IGF-I excess improves psychological subscale appearance. European Journal of Endocrinology 2008158 305-310. (doi:10.1530/EJE-07-0697)

25 Bex M, Abs R, T'Sjoen G, Mockel J, Velkeniers B, Muermans K \& Maiter D. AcroBel - the Belgian registry on acromegaly: a survey of the 'real-life' outcome in 418 acromegalic subjects. European Journal of Endocrinology 2007157 399-409. (doi:10.1530/EJE-07-0358)

26 Schöfl C, Franz H, Grussendorf M, Honegger J, Jaursch-Hancke C, Mayr B \& Schopohl J. Long-term outcome in patients with acromegaly: analysis of 1344 patients from the German Acromegaly Register. European Journal of Endocrinology 2013168 39-47. (doi:10.1530/eje-12-0602)

27 Sesmilo G, Gaztambide S, Venegas E, Pico A, Del Pozo C, Blanco C, Torres E, Alvarez-Escola C, Fajardo C, Garcia R et al. Changes in acromegaly treatment over four decades in Spain: analysis of the Spanish Acromegaly Registry (REA). Pituitary 201316 115-121. (doi:10.1007/s11102-012-0384-x)

28 Vallette S, Ezzat S, Chik C, Ur E, Imran SA, Van Uum S, Rivera J, Caspar-Bell G \& Serri O. Emerging trends in the diagnosis and treatment of acromegaly in Canada. Clinical Endocrinology 201379 79-85. (doi:10.1111/cen.12112)

29 Carlsen SM, Svartberg J, Schreiner T, Aanderud S, Johannesen O, Skeie S, Lund-Johansen M, Fougner SL, Bollerslev J \& POTA Study
Group. Six-month preoperative octreotide treatment in unselected, de novo patients with acromegaly: effect on biochemistry, tumour volume, and postoperative cure. Clinical Endocrinology 201174 736-743. (doi:10.1111/j.1365-2265.2011.03982.x)

30 Roset M, Merino-Montero S, Luque-Ramirez M, Webb SM, LopezMondejar P, Salinas I, Soto A, Bernal C, Villabona C, De Luis D et al. Cost of clinical management of acromegaly in Spain. Clinical Drug Investigation 201232 235-245. (doi:10.2165/11599680-00000000000000)

31 Didoni G, Grottol S, Gasco V, Battistini M, Ferone D, Giusti M, Ragazzoni F, Ruffo P, Ghigo E \& Minuto F. Cost-of-illness study in acromegalic patients in Italy. Journal of Endocrinological Investigation 200427 1034-1039. (doi:10.1007/BF03345306)

32 Bolin K, Gip C, Mork AC \& Lindgren B. Diabetes, healthcare cost and loss of productivity in Sweden 1987 and 2005 - a register-based approach. Diabetic Medicine 200926 928-934. (doi:10.1111/j.14645491.2009.02786.x)

33 Ericson L, Bergfeldt L \& Bjorholt I. Atrial fibrillation: the cost of illness in Sweden. European Journal of Health Economics 201112 479-487. (doi:10.1007/s10198-010-0261-3)

34 Jansson SA, Ronmark E, Forsberg B, Lofgren C, Lindberg A \& Lundback B. The economic consequences of asthma among adults in Sweden. Respiratory Medicine 2007101 2263-2270. (doi:10.1016/j. rmed.2007.06.029)

35 Lundqvist A, Andersson E \& Steen Carlsson K. Kostnader för cancer i Sverige idag och år 2040 (Costs of cancer in Sweden today and year 2040; Report in Swedish). ISSN: 1651-7598, 2016.

36 Olsson DS, Andersson E, Bryngelsson IL, Nilsson AG \& Johannsson G. Excess mortality and morbidity in patients with craniopharyngioma, especially in patients with childhood onset: a population-based study in sweden. Journal of Clinical Endocrinology and Metabolism 2015100 467-474. (doi:10.1210/jc.2014-3525)

37 Olsson DS, Nilsson AG, Bryngelsson IL, Trimpou P, Johannsson G \& Andersson E. Excess mortality in women and young adults with nonfunctioning pituitary adenoma: a Swedish nationwide study. Journal of Clinical Endocrinology and Metabolism 2015100 2651-2658. (doi:10.1210/jc.2015-1475)

Received 27 July 2016

Revised version received 3 November 2016

Accepted 15 November 2016 